\title{
Vulnerabilidades e marginalização no mundo do trabalho da prostituição
}

\author{
Vulnerabilities and marginalization in the ord of prostitution work
}

\author{
Ana Rosa Ribeiro Elias \\ Marcelle Aparecida de Barros Junqueira \\ Isabel Cristiane de Noronha \\ Janaína Pereira \\ Carla Denari Giuliani \\ Maria Cristina de Moura Ferreira
}

\begin{abstract}
Resumo
Este texto aponta diferentes compreensões da atividade de prostituição no contexto social e analisa esse tema enquanto atividade laboral inserida no mundo do trabalho. Nesse sentido, discute as intersecções dessa atividade junto a Política Nacional da Saúde do Trabalhador e da Trabalhadora, bem como as vulnerabilidades e riscos laborais implicadas nesse contexto.

Palavras-chave: Prostituição; Saúde do Trabalhador; Riscos Ocupacionais
\end{abstract}

\begin{abstract}
This text points out diferent understandings of the activity of prostituition in the social context and analyzes this theme as a labor activity inserted in the world of work. In this sense, it discusses the intersections of this activity with the National Workes and worker Health Policy, as well as the occupational hazards and vulnerabilities implied in this context.
\end{abstract}

Keywords: Prostitution. Worker's Halth, Occupational Risks.

Não estando em atividade, as prostitutas limitam-se ao acesso a determinado direito e/ou bem, encontrando-se em vulnerabilidade social, necessitando lançar mão de medidas que consolidem a cidadania da coletividade, o que é impossível dentro da lógica capitalista que as exclui (SILVA, 2011).

Percebe-se como consequência que a luta contra essa exclusão se reduz a uma emergência social, com propostas momentâneas ao contrário de ações preventivas com mudanças reais. $\mathrm{O}$ que para alguns autores o conceito 
de exclusão é incerto, pois o que encontram são vítimas de sistemas sociopolítico-econômicos excludentes (NEUHOLD, 2004).

O conceito de exclusão possui duas características: a primeira relacionada com a ausência de emprego, com indivíduos dispensáveis economicamente; a segunda diz respeito ao indivíduo dispensável socioeconomicamente, que como ameaça social deve ser extinto (OLIVEIRA, 1997).

A sociedade capitalista, segundo o sociólogo José de Souza Martins (1997), maltrata a todos, priva a todos, em circunstâncias diversas, e de inúmeras formas, torturantes ou não, acabamos desprezados. Ela desenraiza, exclui, para incluir, segundo suas próprias regras, precária, marginal e instável (BRITO, 2008).

O sociólogo afirma que tal passagem de momento implica certa degradação, de modo que a sociedade moderna vem criando uma grande massa da população restante com poucas chances de ser inserida nos modelos de crescimento atuais. Isto é, o que teria de ser temporário acaba tornando-se num meio de vida constante, com a criação de uma sociedade paralela, inclusiva na perspectiva financeira e excludente na perspectiva moral e sociopolítica.

A inclusão ocorre no plano econômico, pois o indivíduo recebe algo para subsistir, porém o mesmo não acontece na área social e nem sem causar deformações morais, encontrando-se na zona de vulnerabilidade (emprego insatisfatório e fragilidade de apoios relacionais). Já a exclusão não é arbitrária, mas legitimamente identificada, consequência de sistemas que constituem um real status.

Pobres adentram o mundo do consumo tornando-se cúmplices do mundo responsável por sua pobreza. O que importa é consumir independente dos meios degradantes, precários, ilícitos e violentos que são necessários para chegar neste (NEUHOLD, 2004).

Dentro desse contexto geral de inclusão, é fundamental pensar, antes do lugar da prostituta, o da mulher. Ainda em meados deste século, a mulher trabalhadora, mesmo com maior aprovação social, continua ocupando, na maioria das vezes, hierarquicamente lugar inferior, associada principalmente à figura da mãe e boa companheira. Soma-se a isso o fato de Caderno Espaço Feminino | Uberlândia, MG | v.31 | n.2 | seer.ufu.br/index.php/neguem | jul./dez. 2018 | ISSN 1981-3082 302 
que casamento e trabalho são para muitos inconciliáveis, seja pelo envolvimento profissional que prejudica a dedicação à família ou porque homens gostam de mulheres dependentes. Como exemplo, nos anos de 1950 e 60, houve proximidade nos sexos em termos numéricos no ensino médio, mas as mulheres seguiram atividades profissionais de menor remuneração e prestígio (PINSKY; PEDRO, 2012).

Com relação ao trabalho e saúde, diversos fatores no cotidiano de trabalho das profissionais do sexo, são capazes de alterar sua saúde mental e física, como, por exemplo, aspectos como violência e agressão física por parte dos atritos com a polícia, clientes, omissão da atividade de parentes e conhecidos, além da divergência de princípios com a realização do sexo rentável, potenciais fontes de estresse e de depressão. Tais fatores são considerados elementos representativos de perigo ao corpo, podendo desencadear desgaste mental e sofrimento, tem-se a sobrecarga de trabalho, inconstância de turno e ambiente, condições de emprego insatisfatórias, exploração e marginalização social (SILVA; COSTA; NASCIMENTO, 2010).

No que diz respeito à prostituição, a discriminação faz com que o aproveitamento e o abuso nas condições de emprego sejam ainda mais exacerbados. A caracterização penal sem as organizações públicas de proteção social coloca muitos profissionais em desacordo com a normatização da profissão. Pois, caso se criasse um cadastro de profissionais do sexo, as que fossem acometidas por doenças seriam impedidas, mas sem a devida previsão de assistência a doença ou reabilitação profissional por parte do regime de Previdência Social, como exemplo (WESTPHAL; BARBOSA, 2012).

\section{Conceito e apontamentos históricos}

A palavra prostituição é definida como a prática de entregar-se a relações sexuais por dinheiro. O vocábulo prostituição tem derivação do latim prosto, que tem sentido de estar à vista, ao aguardo de quem surgir ou estar explícito ao público. Cabe destacar-se que é indiferente do sexo do indivíduo, identificando-se como o ato de uma pessoa que faz sexo, por um valor combinado de dinheiro ou substitui-o por qualquer outro bem (DECS, Caderno Espaço Feminino | Uberlândia, MG | v.31 | n.2 | seer.ufu.br/index.php/neguem | jul./dez. 2018 | ISSN 1981-3082 303 
2014; FRANÇA, 2012; GASPAR, 1988 apud OLTRAMARI; CAMARGO, 2004).

Foucault (2014) através da análise do livro de Artemidoro, intérprete dos sonhos do século II d.C., coloca que as mulheres são nos sonhos as cenas das atividades pertinentes ao sonhador. Portanto, independente da mulher e condição em que essa se encontre, é nessa condição que sua ocupação envolverá o sonhador. Pode-se ter acesso a três tipos de mulheres: esposa, amante e prostituta. Entre a esposa e amante não há diferença, o prazer com que se tem com sua relação anuncia o prazer com se terá com os benefícios da relação.

Já quanto à prostituta é diferente. Enquanto objeto do qual se obtém prazer, possui valor positivo; às vezes chamadas pelo vocabulário familiar de trabalhadoras - dispostas a proporcionar esses prazeres sem recusas. Mas, há vergonha e gastos com usufruir dos serviços desse tipo de mulher. Implica significações favoráveis ao ser chamado de ateliê e de cemitério, o trivial. E o outro lado, evocado pela ética sexual dos médicos e filósofos, o desperdício do esperma sem o benefício da descendência que a mulher pode assegurar que no sonho pode supor a morte relacionar com prostitutas (FOUCAULT, 2014).

A prostituição caracteriza-se como uma prática que desfaz o comportamento socialmente esperado da mulher, com o padrão tradicional, de esposa e mãe. Assim, a sexualidade no casamento é identificada como sadia e a prostituição, ao romper com os níveis de aprovação da sexualidade feminina, representa a doença, o risco de acabar com o casamento (MOURA, 1992).

Além disso, está associada à ideia de perda do patrimônio, mas essencial para a preservação das instituições sociais - dentre as quais a familiar, frente aos desejos masculinos que não conseguem ser contidos, assim como às parafilias consideradas mais graves.

Discutir sobre sexualidade diz respeito a analisar o próprio caráter desta e suas correlações, os eixos que se estabelecem são: formação dos saberes relacionado a ela, os sistemas de poder que regulam sua prática e as formas pelas quais os indivíduos se identificam como sujeitos dessa sexualidade (FOUCAULT, 1984). 
O receio da sociedade com relação à prostituição não é porque ela se contrapõe à família, mas sim porque compõe a família, na medida em que está inserida nas relações familiares, considerada parte obscura das muitas relações familiares (MARINS NUNES, 2016).

A prostituição é tão antiga quanto a história da humanidade, sendo associada à desonestidade, degradação e falta de autonomia em decorrência de preconceitos e estigmas. Estando presente em todas as épocas, da mais remota Antiguidade até hoje, e em todos os cantos do mundo (DUARTE; VANZ, 2008; SCHREINER et al., 2004; TOMURA, 2009; TORRES; DAVIM; COSTA, 1999).

Santo Agostinho admitiu a prostituição como um mal necessário; Carlos Magno baixou um édito em seu favor; dentre tantos outros cidadãos ilustres e respeitados que cometeram o erro de transformar a prostituta em maravilha antes de percebê-la como indivíduo. Mulheres anônimas inventando nome para não serem esquecidas, pois o verdadeiro nome que as diferenciava desfez-se em um modo de vida em que tudo se confunde e assemelha-se (FRANÇA, 2012).

A prostituição é também a mais antiga das profissões a sofrer até os dias atuais com a marginalidade, pelas condições sociais impostas, das mais penosas, indigna e estigmatizadas, especialmente em virtude das condições desumanas, degradantes nas quais é exercida, por muitas profissionais do sexo (MARINS NUNES, 2016).

Falar de sexualidade, mesmo que seja nos dias atuais, é polêmico e de difícil abordagem, pois, de maneira mais ou menos intensa, a prostituição sofre restrições sendo colocada à beira da sociedade, visto que é contraditória às normas sociais, despreza os limites exigidos por uma sociedade conservadora que, simultaneamente a incrimina, possui prática semelhante (BASSERMANN, 1968 apud SCHREINER et al., 2004; GOUVEIA et al., 2010; NICOLAU; AQUINO; PINHEIRO, 2008).

Durante o período de colonização do Brasil, os homens que vieram explorar as terras não trouxeram suas famílias. Como forma de satisfazerem seus desejos sexuais e se aproximarem dos índios da terra, mantinham relações sexuais com as índias, que quando as engravidavam, viravam parentes dos índios, obtendo auxiliares para carregar o pau-brasil até os Caderno Espaço Feminino | Uberlândia, MG | v.31 | n.2 | seer.ufu.br/index.php/neguem | jul./dez. 2018 | ISSN $1981-3082305$ 
navios (RIBEIRO, 1995 apud PUC-Rio, 2011).

A sexualidade indígena era vista como desregradada, ameaçadora ao processo de colonização, pois os prazeres sexuais estavam ligados às concepções culturais dos povos nativos e não aos padrões dos europeus cristãos. Os índios praticavam o sexo no momento em que, do jeito que, com quem e no lugar que queriam, sem proibição. Tinham o costume de ter várias mulheres, transmitir seus valores à noite e práticas sexuais não reprodutivas, como exemplo a sodomia (PRIORE; AMANTINO, 2011).

Porém, tal fato deixou a Igreja Católica apreensiva com a rapidez das gestações e a miscigenação que acontecia. Quando em 1549, o padre Manoel Nóbrega encarregado pelos jesuítas no Brasil, solicitou ao rei que viessem mulheres brancas portuguesas a fim de se casarem e reproduzirem com os colonizadores, com a finalidade de tornar a raça branca predominante (NOBREGA, [15--?] apud PUC-Rio, 2011).

Assim, foram enviadas pelo rei meninas órfãs, prostitutas, assassinas, ladras, com o objetivo de reproduzir com os portugueses na colônia.

No século XVII, São Paulo progrediu com a descoberta do ouro em Goiás, Mato Grosso e Minas Gerais, e devido à dificuldade de acesso, somente por forte necessidade se justificava ir até este, tornando-se local de refúgio para fugitivos da justiça. Iniciaram-se as primeiras casas de prostituição no século XVIII, com a descoberta do ouro em Cuiabá, como ponto de passagem para forasteiros, criminosos, prostitutas que se preparavam para a exploração das minas. Mas, nesse período, também começou a ocorrer punição para os que perturbavam a ordem, com o isolamento da sociedade, abrangendo tanto prostitutas como adúlteras, que acabaram enviadas para regiões desertas (FONSECA, 1982).

Com a chegada de Dom João VI ao Rio de Janeiro, a prostituição foi enobrecida por outros tipos de mulheres, provenientes dos Açores e França. Assim, o Rio, na segunda metade do século XIX, tinha uma população muito numerosa e a oportunidade de emprego reduzida para indivíduos livres e despossuídos. Assim, as mulheres, com o preconceito que sofriam, acabavam por ter suas ocupações restritas, encontrando na prostituição a opção com maior expressividade de ganhos, com um perfil econômico sociocultural diversificado, composto por escravas, mulheres livres estrangeiras ou Caderno Espaço Feminino | Uberlândia, MG | v.31 | n.2 | seer.ufu.br/index.php/neguem | jul./dez. 2018 | ISSN 1981-3082 306 
brasileiras (ENGEL, 2004).

Em 1845, a prostituição foi dividida no Rio de Janeiro em três classes: aristocratas ou de sobrado (instaladas em bonitas casas, símbolo burguês do negócio, mantidas por fazendeiros e ricos políticos), as de sobradinho ou de rótula (trabalhavam em hotéis ou nas casas de costureiras em Botafogo ou no Jardim Botânico; ficavam em praças, mercados e ao longo das paredes importantes das avenidas à espera de clientes) e as da escória (moradoras de casebres e em cortiços) (PRIORE, 2017).

O prostíbulo servia como uma fuga para a sociedade que trabalhava de dia e possuía várias fraquezas sexuais e morais, com diversas formas de lazer e inclusive negócios políticos eram realizados ao som de músicas animadas e mulheres disponíveis sexualmente (PRIORE, 2017).

No final do século XIX e início século XX, a prostituição ganhou espaço na sociedade brasileira, com homens de várias classes sociais frequentando bordeis e zonas de meretrício. Estas até hoje funcionam com leis, códigos e práticas próprias, consideradas espaço de interação social. A partir daí, começaram a vir mulheres de outros países em contrapartida à diferença entre o número de homens e mulheres que havia e a tal prática não sofrer repressão, o que permitia corrupção nos meios políticos e policiais, permitiu-se até a entrada ilegal destas (RAGO, 2008).

Conhecidas como francesas (falsas ou verdadeiras francesas) e polacas (provenientes do Leste Europeu de origem judaica), vieram para o Brasil no mesmo período atuar no mundo da prostituição. Experientes ou não, começaram na profissão após serem iludidas por homens pertencentes ao tráfico internacional de mulheres. Viam na emigração uma forma de encontrar trabalho para fazer alguma fortuna e quando chegavam eram obrigadas a se prostituir para sobreviver. Levavam uma vida difícil, propensas a maus-tratos e sob ameaça de rufiões que em troca de não entregá-las para a polícia por serem clandestinas, não pagarem dívidas com a viagem ou hospedagem, ou qualquer outro motivo, detinham o domínio sobre seus corpos. Algumas chegavam a trabalhar por conta própria, outras tornavam-se proprietárias de prostíbulos (PINSKY; PEDRO, 2012).

A procura pelos serviços das profissionais do sexo era determinada por alguns aspectos sociais: as normas de comportamento, os padrões e Caderno Espaço Feminino | Uberlândia, MG | v.31 | n.2 | seer.ufu.br/index.php/neguem | jul./dez. 2018 | ISSN 1981-3082 307 
valores morais vigentes (o patriarcalismo, monogamia, valorização da virgindade) que concederam ao homem libertinagem insuspeita e tolerada socialmente (ENGEL, 2004).

No Brasil, os higienistas responsabilizavam as prostitutas pela degradação moral e física do homem e consequente destruição das famílias e crianças, que a retiravam do mundo e obrigavam a amamentar o filho, domesticando-a. A mulher com perturbação era indispensável ao poder médico, que diante da variabilidade etiológica permitia sua emancipação do patriarca colonial e a submissão ao compromisso higiênico de alimentar tanto os filhos, quanto o machismo masculino (COSTA, 2004).

A fim de manter a estabilidade das famílias e sociedade brasileira, autoridades policiais e médicos empenhavam-se em planos de combate ao aumento e contenção da prostituição, analisando a necessidade de sua regularização. A prostituição era considerada uma ameaça para o trabalho segundo as autoridades policiais, com a visão de uma vida fácil e luxuosa, alcançada com a perda dos bens de muitas famílias, de quem os patriarcas cediam aos atrativos das prostitutas, não medindo gastos para presenteálas. Somado a isto, representavam para a saúde pública prejuízo com a transmissão de sífilis e outras doenças venéreas, provocando angústia e morte na população (VAINFAS, 1986).

Os brasileiros obtiveram nova cultura sexual com os prostíbulos (PRIORE, 2017). O rito de iniciação sexual passou a ser exercido pelas prostitutas e práticas sexuais diferenciadas eram usadas com os adultos mais velhos, que não poderiam realizá-las com suas esposas. Os mais novos conseguiriam satisfazer parte de seus desejos sexuais com estas a fim de no futuro se adaptarem e conviverem com suas esposas castas sem grandes excitações (RAGO, 2008).

A partir de meados do século XIX, o discurso médico-sanitarista valorizava a mulher como protetora do lar, com a função divina da maternidade e com predisposição normal de procriação e educação dos filhos, atacando o abandono infantil, a amamentação mercenária e a prostituição, vista como obsessão, necessitando ser represada evitando práticas condenáveis, desconhecidas e clandestinas. As prostitutas são classificadas como pervertidas, com repulsa ao trabalho e obsessão Caderno Espaço Feminino | Uberlândia, MG | v.31 | n.2 | seer.ufu.br/index.php/neguem | jul./dez. 2018 | ISSN 1981-3082 308 
descontrolada por prazer. Políticas médicas e criminológicas são vistas como técnicas de poder destinadas a enclausurar e a domesticar práticas sexuais extraconjugais, como a instituição de padrões de comportamento da mulher honesta da vagabunda (RAGO, 2014).

O médico cria a imagem da prostituta, com a construção da ideia da prostituição como uma doença corporal que o corrói, ameaçando outros corpos, sendo assim a ameaça da contaminação. Assim, a prostituição é vista como lugar da perversão, da esterilidade, da sexualidade doente, além da doença moral, uma ameaça aos costumes das famílias honestas (VAINFAS, 1986).

A conduta familiar estabelecida pela ordem médica solicita com frequência a presença de intervenções disciplinares por parte dos responsáveis pela normatização. Tais intervenções, nos dias atuais, são apontadas como causas da fragmentação familiar, consequência da educação higiênica, normas estas que lhes foram impostas. Através da tutela terapêutica corpo, sexo e relações afetivas entre integrantes da família, começaram a ser utilizados de modo calculado e sistemático, como meio de reprodução e manutenção da ordem social burguesa, um modo de regulação politica da vida do indivíduo. O trabalho de persuasão higiênica era construído sobre a ideia de que a saúde e prosperidade da família dependiam da submissão ao Estado (COSTA, 2004).

A comunidade médica, juntamente com a polícia, nos anos de 1870, propôs algumas medidas para combater a expansão desenfreada do meretrício com a criação de locais para controlar a moral e o físico das prostitutas (as consagradas áreas de prostituição); exames médicos periódicos; assinatura de um termo de conveniência, e sua sujeição a normas específicas. Mas as prostitutas acabaram por não ter controle e inspeção médico-policial e nem se localizaram em um local determinado, ficando espalhadas desorganizadamente pela cidade devido à não política de regularização e normalização do meretrício, que não foi nem cogitada pelos homens com poder (VAINFAS, 1986).

Nos estudos feministas, a prostituição tem sido vista de forma contrária. Para o feminismo radical, com origem no final do século XIX, as prostitutas são vistas como vítimas da opressão masculina, expressão Caderno Espaço Feminino | Uberlândia, MG | v.31 | n.2 | seer.ufu.br/index.php/neguem | jul./dez. 2018 | ISSN 1981-3082 309 
máxima da submissão feminina, devendo ser suprimida a atividade, por permitir a realização dos mais graves crimes de natureza sexual. Já para o feminismo liberal, com sua origem nas décadas de 80 e 90, representado pela atuação dos movimentos organizados de prostitutas, a prostituição é um ato de autodeterminação sexual, sendo um trabalho como outro qualquer, com a sexualidade da mulher pertencente a esta, sendo considerada livre (BARRETO, 2008; RODRIGUES, 2009).

Há no mínimo três motivos que sugerem a necessidade de uma percepção menos inferiorizada da prostituição por parte das feministas, o que permitiria uma parceria mais equitativa e próxima entre feministas e profissionais do sexo (JULIANO, 2004):

- Coerência lógica: não desvalorização da atividade sexual por cobrar por um trabalho que é algo legítimo, e visualização como capacidade de escolha dentre os vários meios como o trabalho se caracteriza.

- Coerência ideológica: ser feminista resulta em um olhar da mulher como ator social preparado para trabalhar com um grau de autonomia.

- Verificação da capacidade de questionamento da prostituição: a perspectiva de prostitutas de preservarem o modo patriarcal sem prejudicar a sociedade (emprego, sistema jurídico, família).

Rago (2014) evidenciou três núcleos de problematização dos anarquistas que procuraram definir uma nova economia do desejo: a emancipação da mulher com ênfase no ataque à Igreja e ao Estado; as relações afetivas e a moral sexual, com crítica ao mito do amor materno, assexualidade, casamento monogâmico, virgindade, dentre outros; e as práticas condenáveis, sobre o carnaval, baile, álcool, fumo e futebol como vícios, promovidos pela classe dominante, que enfraquecem e entorpecem a classe operária.

Desde meados do século XIX até os dias atuais, pode-se citar como exemplo, a prostituição feminina em Portugal, a qual possui tratamento sociopolítico e jurídico-legal sob jurisdição do Estado, com delimitação sobre a sexualidade feminina entre o contraste das mulheres recatadas e as mulheres não recatadas. Onde na segunda metade do século XIX, à 
semelhança do que acontecia na Europa ocidental, nesse país ocorreram esforços legislativos tentando evitar a contaminação das mulheres recatadas, procurando maneiras de mantê-las no lar, e concomitantemente empenhou-se em regularizar a prostituição, criando a exigência da inscrição policial para inspeção sanitária periódica. Assim, surgiram regras municipais iniciais contra a prostituição, entre 1858 e 1865 - as prostitutas passariam a ser invisíveis para quem não deveria saber da sua existência, mas visíveis, identificáveis e localizáveis para os poderes, que facilmente exerceriam um controle sobre as mesmas (SILVA, 2007).

As décadas de 1960, 1970 e 1980 assistiram o crescimento das profissionais do sexo em várias partes do mundo, com novas formas de pensar e intervir sobre a prostituição, com características específicas em cada localidade, embora tenham tido origem na luta contra violências policiais e vínculo inicial com grupos religiosos, o momento consolidou também os movimentos de mulheres e feministas. No Brasil, a principal luta era contra a ditadura, o que marcou profundamente o posicionamento dos movimentos feministas e de prostitutas. Já nos EUA ocorria o movimento da guerra dos sexos e luta contra a AIDS/HIV (BARRETO, 2015).

A AIDS/HIV não foi vista inicialmente como pauta feminista, mas sim como um cancro homossexual, que posteriormente foi alterada para abranger outras conhecidas categorias de risco (atualmente conceito não mais utilizado, pensando-se em termos de vulnerabilidades), como o caso das prostitutas. Mas, por dificuldade de algumas feministas em aceitar e legitimar as reivindicações e lutas das profissionais do sexo, somado a isso a colocação destas como grupo de risco e assim como, ponto de intervenção, levou-se, no final de 1980, ao fato de que a pauta de ação e financiamento para intervenção fosse a AIDS nos movimentos de prostitutas (BARRETO, 2015).

No início da década de 1990, começou no Brasil uma organização formada por prostitutas para a reivindicação de seus benefícios sociais como cidadã, assim como a legalização da prostituição como trabalho. Foram fundados a DAVIDA (1992), Prostituição, Direitos Civis e Saúde e a edição do jornal Beijo da Rua. Posteriormente, em 1993, foi criado o NEP (Núcleo de Estudos sobre a Prostituição), em Porto Alegre, um movimento de lutas Caderno Espaço Feminino | Uberlândia, MG | v.31 | n.2 | seer.ufu.br/index.php/neguem | jul./dez. 2018 | ISSN 1981-3082 311 
dos assuntos relacionados às políticas públicas, de engrandecimento da prostituta como profissional solicitando a normatização dessa ocupação (MARINS NUNES, 2016).

A Rede Brasileira de Prostitutas (RBP), associação nacional de proteção dos direitos das profissionais do sexo, formada por mais de 30 organizações de classe e a Organização Não Governamental (ONG) DAVIDA defendem o direito das prostitutas, a regulamentação da profissão e são contra a ideia de vitimização. Em vista disso, exercem e se reconhecem com a expressão prostituta, para fins de cunho político, uma política de confronto, contra a mascaração do termo, mas de utilizar-se do peso do nome posicionando-se politicamente como postura de enfrentamento e identidade do grupo, mesmo que o nome tenha possível conotação negativa (MARINS NUNES, 2016).

\section{A prostituição enquanto trabalho}

No sistema capitalista, mercantilista universal, há forte contradição entre a função dos profissionais do sexo e a moral burguesa, onde há uma duplicidade de princípios de acordo com os sexos: do homem estabelece-se um comportamento de progenitor, é permitida a procura constante por sexo fora do matrimônio; da mulher, estabelece-se a lealdade matrimonial aceitando-se o sexo apenas no matrimônio (WESTPHAL; BARBOSA, 2012).

Os autores relatam que o homem encontra como possibilidades o adultério e a prostituição. O adultério constitui um vínculo que resulta em intimidade entre os adúlteros. Já a prostituição apresenta o benefício de dispensar envolvimentos amorosos por possibilitar uma profissional que estará à disposição, a qualquer momento, levando a vida de forma obscura e sem dispor de outra realidade além da profissional.

A diferença entre outras atividades laborais e a prostituição consiste, especialmente, nas vulnerabilidades que as profissionais do sexo encaram como trabalhadoras, do qual o desempenho das atividades, assim como em outras profissões, encontra-se permeado por algumas formas de agressão e sem as condições sanitárias, trabalhistas e previdenciárias adequadas, bem como sem atendimento especializado em saúde (MARINS NUNES, 2016). 
A prática da prostituição por si só, no Brasil, não é considerada crime. A exploração, a intermediação e a indução de pessoas à prostituição é que são entendidas crimes perante o Código Penal Brasileiro (CPB). Conforme os artigos 227 e 231 do $\mathrm{CPB}$, no que diz respeito aos crimes contra os costumes, crime é o lenocínio e o tráfico de mulheres, isto é, a especulação da prostituição de outrem (ANDRADE, 2001; ASSIS, 1982 apud SCHREINER et al., 2004; GARCIA, 2016; GOUVEIA et al., 2010; SILVA et al., 1998 apud DUARTE; VANZ, 2008). Sendo assim, os autores afirmam que podem ser enquadrados em crimes proprietários de casas de programa e hotéis e cafetões. Portanto, a prostituição não é julgada crime quando é por vontade própria, mas se a pessoa for induzida, convencida ou atraída por alguém a praticar relação sexual com outros isso caracteriza ação criminosa. Esta ocorre, então, nos casos em que se impede que alguém saia da prostituição, se o indivíduo for sustentado ou tiver lucro com a prostituição de outrem ou possuir estabelecimento de prostituição. Nestas circunstâncias a pena prevista é de reclusão de 1 a 10 anos e multa.

Dentre as formas de prostituição identificadas hodiernamente no Brasil, pode-se enumerar a prostituição de rua (mariposas, streetwalkers ou trottoir), em prostíbulos (rendez-vous, puteiros ou casas de massagem), boates e casas de show e serviços de acompanhantes. Cada uma dessas modalidades possui singularidades que permitem a prestação de serviços diversificada, entre profissionais e o público recebido (WESTPHAL; BARBOSA, 2012).

Quanto às casas de prostituição, a princípio observou-se um crime sem vítima, exceto quando está em discussão a relação com incapaz ou quando a atividade é violenta e causa danos ao corpo da mulher, realizada dentro de localidade marginal que decorre de práticas de extorsão, maus-tratos, cárcere privado, ou detenção contra os envolvidos nas atividades (MARINS NUNES, 2016).

Um fato a ser observado no Código Penal de 1830 é que este não aborda a prostituição e suas formas, mas distingue as mulheres adequadas das prejudiciais, o qual torna-se inconfundível na pena de estupro, no caso da mulher considerada decente para a julgada como vulgar. Além disso, até 2004, só eram considerados consumados crimes de posse sexual mediante Caderno Espaço Feminino | Uberlândia, MG | v.31 | n.2 | seer.ufu.br/index.php/neguem | jul./dez. 2018 | ISSN $1981-3082 \quad 313$ 
fraude e atentado ao pudor se a vítima fosse mulher decente. Somente em 2005 o referido conteúdo foi suprimido do Código Penal, por meio da publicação da Lei 11.106 (BARRETO, 2008).

Destacou-se que em 2012 ocorreu a proposição de atualização do Código Penal Brasileiro, do Projeto de Lei $\mathrm{n}^{0}$ 236, que estabelece novas regras a esses crimes. A exploração sexual é abordada no Título IV 'Crimes contra a dignidade sexual', Capítulo I - 'Crimes contra a liberdade sexual', com a nota no artigo 183: obrigar alguém a exercer a prostituição ou impedir ou dificultar que a abandone. Com esse texto, o legislador distingue prostituição de exploração sexual, proporcionando a oportunidade de reflexão da prostituição como um emprego, devido à diferenciação entre exploração sexual e prostituição (PISCITELLI, 2012).

As prostitutas vivem em condições próximas da clandestinidade, pois, mesmo a atividade sendo legal, é rodeada de condutas e ambientes que manifestam a ilegalidade, circunstância que as condena a trabalharem em muitos transviamentos e estado de vulnerabilidade, com espaços físicos e juridicamente inadequados para atuarem de forma digna no exercício da profissão (MARINS NUNES, 2016).

Estudos indicam que há uma estimativa de que a população de profissionais do sexo no Brasil seja em torno de 1\% da população feminina na faixa etária de 15 a 49 anos, ou seja, em torno de meio milhão de mulheres, segundo dados do Ministério da Saúde (2006 apud DAMACENA; SWARCWALD; BARBOSA JÚNIOR, 2011).

Segundo um estudo da fundação francesa Scelles, que luta contra a exploração sexual, no mundo, mais de 40 milhões de pessoas se prostituem atualmente. A grande maioria entre 13 e 25 anos (75\%), sendo 90\% delas ligadas a cafetões (COLLING; TEDESCHI, 2015).

É possível fazer uma diferenciação da negociação do programa, a qual nem sempre se dá em torno do dinheiro, primeiramente a partir do uso social que as mulheres fazem do próprio corpo, e, em seguida, considerando a questão monetária. O que está em questão é se a mulher possui estrutura física ou não para a prática sexual requisitada pelo cliente. É evidente que o dinheiro deixa de ser importante, tornando-se significativo o uso que o indivíduo faz do próprio corpo (ALVES, 2011). 
Através desta análise, demonstram-se diversas implicações no ambiente prostitucional, dentre elas os limites corporais simbólicos, criados para o contato social, com práticas e algumas partes do corpo indisponíveis aos clientes, disponibilizadas apenas por quem as prostitutas possuem afeição. Entre estas está, por exemplo, beijar, fazer sexo anal, não usar preservativo e dormir com a pessoa envolvida (ALVES, 2011). Existe, então, uma diferenciação entre a vida das profissionais do sexo no exercício da função e fora dela, entendendo-se, para isso, as particularidades dos sujeitos sociais que são, o que abarca além do cuidado com o uso do preservativo, a não disposição do toque nas mamas, muito menos fazer sexo oral e anal (PASINI, 2000).

Algumas profissionais do sexo consideram que quanto menor o tempo com o cliente, mais profissional é a relação - entendendo que os contatos rápidos permitem menos conflitos. Já as mulheres não tão jovens, distintivamente, dizem que a competência se dá utilizando métodos que façam com que o cliente se prenda a elas e volte com o tempo de atendimento maior e conseguinte acréscimo no valor do programa (GARCIA, 2016).

Como podemos notar em várias ocupações, o trabalho se coloca como fonte de realização e prazer, mas, ao mesmo tempo, como lugar de sofrimento e opressão. Quanto a isso, no caso das prostitutas, estas possuem como reclamação o fato de ter que fazer sexo com pessoas que não gostam ou que estejam bêbadas ou drogadas. Algumas conseguem recusar clientes ou práticas que não queiram, tendo como ponto negativo maior a questão do preconceito e discriminação a que estão submetidas, o que faz com que muitas não tornem pública sua ocupação (BARRETO, 2008; SANTOS et al., 2008). Entretanto, há aquelas profissionais que veem o próprio prazer durante a atividade sexual como positivo, e escolhem técnicas que lhes são mais agradáveis e convenientes, sendo o orgasmo durante o programa natural, afinal pode acontecer de sentirem prazer (GARCIA, 2016).

Elas permutam o prazer que são capazes de oferecer por alguma coisa que possa garantir, ainda que minimamente, a manutenção de suas necessidades diárias. Faz parte do trabalho a negociação do preço do programa que se quer praticar, sendo o sexo oral ou anal mais caro, que 
pode ser negociado durante o programa, correndo o risco de o cliente não querer pagar. $\mathrm{O}$ encontro também pode ser combinado pela vontade da profissional do sexo, que escolhe com quem quer fazê-lo, pois para algumas o cliente tem que ter algo a mais (SILVA; COSTA; NASCIMENTO, 2010).

Há um raciocínio de família/negócio do sexo onde não se pode sentir prazer ao se deitar com vários clientes, mas somente conseguir dinheiro na construção do planejamento pessoal (SALES, 2014).

O aburguesamento da sociedade sistematizou como ideal de sexualidade humano a unidade em amor, sexo, matrimônio e procriação. Dessa forma, a sexualidade fora do casamento (coito pré ou extraconjugal, amor livre), a sexualidade sem amor (masturbação, prostituição), ou a sexualidade sem procriação (sexualidade infantil, homossexualidade, sexualidade do climatério) passaram a ser ilícitas (COSTA, 2004).

Para Foucault (1988), se há rigor na repressão do sexo, é por ser incompatível como trabalho, o qual ao se explorar sua força, poder-se-ia terminar em prazer. Sexo e seus efeitos não são fáceis de entender, mas sua repressão é facilmente analisada. Falar de sexo e sua repressão seria soar como infração instituída.

Considerando o cenário brasileiro, ocorreu no ano de 2002 a inclusão da prostituição na Classificação Brasileira de Ocupações (CBO), que é o documento que identifica e agrupa as atividades que tem importância no mercado brasileiro, o que significa grande avanço nas políticas públicas com relação ao tema prostituição (RODRIGUES, 2009; SOUSA, 2007).

Importa frisar que essa inclusão só ocorreu devido à habilidade de discutir a prostituição enquanto ocupação profissional por várias associações de prostitutas (GARCIA, 2016).

No documento do $\mathrm{CBO}$, a família 'profissionais do sexo', de número 5198, evidencia a diversidade de formas de trabalho que se encaixam sob esta. O termo profissionais do sexo recebe alguns sinônimos (BRASIL, 2017): garota(o) de programa, messalina, michê, meretriz, prostituta, mulher da vida e trabalhador do sexo. Tais nomenclaturas evidenciam não ser a prostituição uma ocupação exclusivamente feminina, podendo ser desempenhada também por homens (michês, garotos de programa), travestis e transexuais. $\mathrm{O}$ debate a respeito da denominação atribuída à Caderno Espaço Feminino | Uberlândia, MG | v.31 | n.2 | seer.ufu.br/index.php/neguem | jul./dez. 2018 | ISSN 1981-3082 316 
prostituição é frequente, tanto na associação de prostitutas como na academia (BARRETO, 2008).

A CBO apresenta como descrição sumária da profissão: buscar programas sexuais; atender e acompanhar clientes; participar de ações educativas no campo da sexualidade. A profissão é desempenhada segundo regras e comportamentos que reduzem a fragilidade da profissão (BRASIL, 2017). Esta apresenta como condição geral de exercício: trabalho autônomo em ambientes e turnos variados, podendo estar expostas às intempéries e discriminação social. Além disso, ameaça de contaminação de IST, agressão, maus-tratos e morte (BRASIL, 2017).

A prostituição requer ainda como formação e experiência: participação em oficinas sobre sexo seguro, ser maior de 18 anos; escolaridade média no intervalo entre o quarto e o sétimo ano do ensino fundamental (BRASIL, 2017).

No item área de atividades, estes tópicos são mais claros. Abaixo, são apresentados alguns dos itens que estão mais diretamente relacionados ao trabalho de profissionais do sexo:

- $\quad$ Buscar programa: agendar o programa; produzir-se visualmente; esperar possíveis clientes; seduzir o cliente; abordar o cliente.

- Minimizar as vulnerabilidades: negociar com o cliente o uso do preservativo; usar preservativos; utilizar gel lubrificante à base de água; participar de oficinas de sexo seguro; identificar Doenças Sexualmente Transmissíveis (DST) [termo em desuso, atualmente identifica-se como Infecções Sexualmente Transmissíveis]; fazer acompanhamento da saúde integral; denunciar violência física; denunciar discriminação; combater estigma; administrar orçamento pessoal.

- Atender clientes: preparar o kit de trabalho (preservativo, acessórios, maquilagem); especificar tempo de trabalho; negociar serviços; negociar preço; realizar fantasias sexuais; manter relações sexuais; fazer streap tease; relaxar o cliente; acolher o cliente; dialogar com o cliente. 
- Acompanhar clientes: acompanhar cliente em viagens; acompanhar cliente em passeios; jantar com o cliente; pernoitar com o cliente; acompanhar o cliente em festas.

- Promover a organização da categoria: promover valorização profissional da categoria; participar de cursos de autoorganização; participar de movimentos organizados; combater a exploração sexual de crianças e adolescentes; distribuir preservativos; multiplicador de informação; participar de ações educativas no campo da sexualidade (BRASIL, 2017).

A prostituta necessita apresentar como competências pessoais: demonstrar capacidade de comunicação, persuasão e ouvir, realizar fantasias sexuais e sensualidade, paciência; planejar o futuro; demonstrar solidariedade aos colegas de profissão; cuidar da higiene pessoal, manter sigilo profissional (BRASIL, 2017).

Como recursos para o trabalho estão: guarda-roupa de trabalho, preservativo, comprovantes de identificação, cartões de visita, papel higiênico, lenços umedecidos, gel à base de água, maquilagem, álcool, acessórios, agenda e celular (BRASIL, 2017).

Em ambos os tópicos (descrição sumária e área de atividade), constatamos os diversos tipos de prática que fazem parte do cotidiano dessas profissionais, e que nem todas realizam tais atividades. É um trabalho por vezes sem associação à relação sexual em si, sendo que a profissional do sexo pode desempenhar o papel somente de acompanhante dos clientes. A diversidade de práticas permite um conhecimento peculiar das profissionais do sexo. Não basta fazer sexo, é necessário conhecer como cativar e realizar a vontade do cliente (BARRETO, 2008).

Segundo Lim (2004, apud BARRETO, 2008), a prostituição, na maioria das vezes, é uma alternativa de emprego mais rápida, com turno de trabalho reduzido e bem gratificada do que outros trabalhos. Suas bases são sólidas, com lucro não só para a prostituta e sua família, mas para os que estão envoltos nessa atividade, algumas vezes organizada, diversificada e sofisticada. Diz que, como qualquer atividade, estabelece trabalho e 
rendimentos, mas não permite o acesso a direitos, devido a prejulgamentos morais, financeiros ou sociais (LIM, 2004 apud BARRETO, 2008).

Já Bindman (2004, apud BARRETO, 2008) aponta alguns problemas encontrados por prostitutas em sua atividade, como trabalho noturno, longos turnos, proprietários obtendo vantagens e a falta de segurança, indicando como poderia ser regulamentado como ocorre com outras profissões, já que todo indivíduo tem direito à liberdade (BINDMAN, 2004 apud BARRETO, 2008).

As prostitutas possuem inúmeras dificuldades no dia a dia. Constantemente veem colegas de serviço sendo violentadas e que a polícia e até mesmo a segurança privada dos prédios onde alugam salas para trabalhar não tratam os casos com a importância que tratam comumente quando chamados por outras pessoas. Revelam que já ocorreram furtos, estupros e ameaças de clientes, diante das quais sentiram frustração e resistência, devido ao tratamento distinto (e marginalizado) que recebem, prevendo que para sua reinvindicação certamente não terá avanço investigatório (GARCIA, 2016).

Garcia (2016) afirma ainda que esse tipo de tratamento não assusta, pelo fato de que a sociedade separa as mulheres entre morais e imorais, frequentemente imputando às reprováveis a denominação de prostitutas. $\mathrm{O}$ que implica estigma ao trabalho desenvolvido pelas prostitutas, já que não são vistas como profissionais, mas sim como mulheres de categoria inferior, pelo que carregam de rejeição moral. Tal fato tem sua origem na ideia de pecado, onde qualquer relação sexual é condenável se não for para fins reprodutivos.

A contradição entre os aspectos positivos e negativos direciona ao fato de que muitas mulheres têm a intenção de sair da prostituição, mas continuam fazendo programa eventualmente (BARRETO, 2008) seja pelo término de um relacionamento amoroso, com dependência financeira, ou por incompatibilidade com a sua inclusão no comércio do sexo, por vontade própria ou da pessoa com quem se relacionava (BARRETO, 2015).

Há mulheres profissionais do sexo que realizam o trabalho com exclusividade, outras por necessidade (quitar gastos), ou prazer (próprio ou com cliente que recompense bem), no espaço entre empregos (férias ou Caderno Espaço Feminino | Uberlândia, MG | v.31 | n.2 | seer.ufu.br/index.php/neguem | jul./dez. 2018 | ISSN $1981-3082319$ 
demissão), quando estão na cidade (a viagem ou se dirigem exclusivamente para fazer programa sem risco de serem reconhecidas por familiares) e até mesmo para inteirar os proventos (BARRETO, 2015).

As profissionais referem omitir seu emprego, especialmente de seus familiares, mesmo sendo um trabalho como outro, mas não aceito. Os vínculos que possuem são frágeis, não somente nas relações interpessoais, bem como no local de trabalho com alta rotatividade de trabalhadoras nestes (SANTOS et al., 2008).

As atividades realizadas, na maioria das vezes, estão na ilegalidade, pois são realizadas corriqueiramente nas ruas, dentro de veículos, em locais não reconhecidos (casas de programa), e em todos esses lugares a atividade do sexo é infração, com relação aos dois primeiros, crime especificado no código penal artigo 233 - "Praticar ato obsceno em lugar público, aberto ou exposto ao público", pena de detenção de três meses a um ano, ou multa com relação ao último, o artigo 229 determina que "Manter estabelecimento em que ocorra exploração sexual”, prisão, de dois a cinco anos, e multa (MARINS NUNES, 2016).

Assim, para as prostitutas, fica explícita a abordagem judiciária diferenciada que possuem por serem profissionais do sexo. Um abuso não é julgado estupro quando cometido contra uma profissional do sexo, visto que estão sempre ao dispor. Um assalto realizado em um ambiente de prostituição não tem importância, visto que os lucros desta atividade não são considerados justificáveis de segurança, visto que são provenientes de uma atividade imoral (GARCIA, 2016).

O meretrício está exposto à exploração assim como qualquer outro trabalho informal ou formal, se não houver regulamentação, fiscalização, proteção jurídica e social. Por isso, são organizadas lutas por reconhecimento pelas prostitutas, por mudanças nas condições sociais e trabalhistas além da batalha contra anulação e submissão dos seus discursos (MARINS NUNES, 2016).

Marins Nunes (2016) cita como exemplo dessa luta o fato de, em 27 de agosto de 2015, o Conselho Internacional da Anistia internacional, com matriz em Dubai, aprovar a decisão pela descriminação da prostituição, pela 
defesa dos direitos humanos das profissionais do sexo. Tal ação autorizava a Junta Diretiva Internacional a compor e reconhecer políticas próprias que discorre a temática com maior especificidade. A secretária-geral da Anistia Internacional (AI) afirmou que os trabalhadores sexuais são uma das classes mais excluídas mundialmente e, na maioria das vezes, vivem sobre ameaça frequente de agressão, estupro e preconceitos.

O Conselho Internacional da Anistia Internacional propõe a organização de política que defenda a descriminação absoluta dos serviços sexuais, e prevê que os governos assegurem aos profissionais do sexo: amparo jurídico imparcial e total, perante situações de violência, abuso e tráfico; redução de danos; integridade física e psicológica (MARINS NUNES, 2016).

O trabalho do sexo deveria ser regulamentado pela legislação laboral e civil comuns às demais categorias profissionais, com o objetivo de que as mulheres sejam reconhecidas como trabalhadoras e que se busquem melhorias em suas condições de trabalho (WIJERS, 2004), atendimento das condições sanitárias, exercício livre da prostituição sem coações e extorsões, aposentadoria por contribuição e associação sindical (MARINS NUNES, 2016).

Mas, mesmo sendo a prostituição reconhecida como trabalho, isso não garantirá o fim das formas de dominação sobre as profissionais do sexo, pois, inúmeros trabalhos são regulamentados e não se assegura a ausência da exploração (BARRETO, 2008).

\section{Contexto social e cultural da prostituição}

A prostituição no Brasil é identificada desde o século XIX. E a cada ano vem aumentando significativamente, sendo a miséria econômica um dos principais motivos para início no mundo da prostituição (AQUINO; NICOLAU; PINHEIRO, 2011; CARVALHO; BORGES, 2003; BRAGA, 1982 apud TORRES; DAVIM; COSTA, 1999; DUARTE; VANZ, 2008; GASPAR, 1998 apud; NICOLAU; AQUINO; PINHEIRO, 2008).

São considerados como fatores para o início nas atividades de prostituição, a miséria e pobreza, a promiscuidade das habitações coletivas, 
a ausência de educação e serviço, os lares desfeitos, o alcoolismo paterno, a infância desamparada. Somando-se a isso há ainda o motivo de buscar por um status social, com possibilidade real de gerar renda rápida e suficiente (CUNHA, 2014; FRANÇA, 2012; GOUVEIA et al., 2010; SOUSA, 2007), além da busca por horários flexíveis, ausência de vontade de ser empregada e o desejo de independência econômica (BARRETO, 2015).

Os autores citam, também, como fatores de risco à submissão, uso de drogas ilícitas e abuso de bebidas alcoólicas, o que leva todos estes aspectos ligados à prostituição a ter importância dentro das ações em saúde, buscando-se atuar na prevenção de riscos ou até mesmo redução de danos com esta população mais vulnerável socialmente que não pode ou não quer abster-se. E, há aquelas que exercem suas práticas camufladas, com medo de serem descobertas, principalmente quando a estão exercendo nos níveis socioeconômicos mais altos (AQUINO; NICOLAU; PINHEIRO, 2011; SALMERON; PESSOA, 2012).

Estas profissionais estão sujeitas ao desenvolvimento de Infecções Sexualmente Transmissíveis (IST) e da Síndrome da Imunodeficiência Adquirida (AIDS), além de violência (agressões, abusos e ofensas), e discriminação, seja pela multiplicidade de parceiros, más condições de trabalho desfavoráveis à prática sexual segura e baixo nível de escolaridade que facilite a percepção do risco (SALMERON; PESSOA, 2012).

Um dos principais desafios enfrentados pela profissional do sexo é a necessidade de convencer o cliente a usar o preservativo (AQUINO et al., 2008).

A escassez de clientes e a concorrência fazem com que as profissionais do sexo tenham dificuldades em comerciar o programa e consentir práticas inseguras. A profissional do sexo sabe da necessidade do preservativo para sua segurança; por outro lado, o cliente nega o cumprimento do pagamento se usá-la (GUIMARÃES; MERCHAN-HAMANN, 2005).

Assim, a fim de evitar a perda do controle de suas ações preventivas e consequente vulnerabilidade, as mulheres também evitavam exagerar na bebida (OLTRAMARI; CAMARGO, 2004).

$\mathrm{Na}$ perspectiva da pobreza, a prostituição seria uma forma de comercialização do corpo por falta de oportunidades, estando diretamente 
relacionada à desigualdade social no país e à questão de gênero (COLLING; TEDESCHI, 2015). Classificada como doença social, representaria uma ameaça à riqueza da nação, visto ser foco de separação do trabalho e da propriedade, produzindo indivíduos inúteis, incapazes para o exercício da cidadania, sendo associada à ideia de luxo, ociosidade, ambição e desperdício (VAINFAS, 1986).

Tendo também as carências afetivas, traumas, ausência de apoio familiar como fatores psicológicos a influenciarem a iniciar no comércio sexual. A prostituição é, muitas vezes, a forma de sobrevivência e consumo (AQUINO; NICOLAU; PINHEIRO, 2011).

Nas sociedades tradicionais, esse menosprezo era feito pela associação com o pecado, mas na sociedade presente, a valorização é associada à posição de trabalhador/a. Assim, negar a indivíduos sua situação de trabalhadores resulta na redução de suas possibilidades de inserção na sociedade como sujeitos plenos de direitos (BARRETO, 2008).

Rua e prostituição, além de estarem relacionadas às doenças infectocontagiosas de cunho sexual, denotam risco para diversos tipos de violência além de comorbidades psicobiológicas, tais como depressão, pânicos e ansiedade, impactando a saúde pública (PERES, 2002; VILLELA; MONTEIRO, 2015).

Pode-se observar que a prostituição tem relação com uma variedade de práticas, sentimentos e ações. Assim, muitos movimentos de prostitutas têm buscado uma visão da prostituição como um trabalho e, como tal, sujeito a explorações (BARRETO, 2008). Mas, a exploração sexual não tem associação com o local em que é realizada, caracteriza-se pela existência de um explorador que obriga a mulher contra o seu desejo, com regulação sobre o provento das partes envolvidas na prestação do serviço, sem cumprimento às acomodações do estabelecimento, que englobam saúde, segurança e condições sanitárias, além das normas trabalhistas (MARINS NUNES, 2016).

A proprietária estipula regras de funcionamento da casa como: não trazer consigo e nem utilizar drogas ilícitas no local (implica em risco para a dona do estabelecimento), não beijar o cliente em público, sair da casa por no máximo vinte minutos durante o expediente, que vai até o último cliente. Caderno Espaço Feminino | Uberlândia, MG | v.31 | n.2 | seer.ufu.br/index.php/neguem | jul./dez. 2018 | ISSN 1981-3082 323 
Caso as regras não sejam cumpridas, a dona do estabelecimento poderia multar as profissionais (SANTOS et al., 2008).

Kempadoo (1998) aponta que ver o trabalho sexual como passível de exploração, tal qual qualquer outro trabalho, pode implicar em bases para a mobilização e lutas por melhores condições de trabalho, direitos e benefícios, bem como para a resistência à opressão, permitindo o surgimento de estratégias para a busca por mudanças (KEMPADOO, 1998 apud BARRETO, 2008).

Contudo, o forte estigma relacionado à prostituição, seu status ilegal e sua exclusão de assistências sociais que normalmente são oferecidas a outras profissões compreendem numa maior vulnerabilidade à transgressão de direitos. Consequentemente, as prostitutas não se reconhecem dignas de direitos e, quando poucas buscam auxílio das autoridades, não o obtém, uma vez que há forte discriminação policial e judiciária (BINDMAN, 2004 apud BARRETO, 2008).

Considerada alternativa de sobrevivência para a mulher pobre, desempregada ou com baixos salários, a prostituição, com a perspectiva de melhores salários, além da viabilização de uma condição mais independente e autônoma, necessita ser vista como espaço de luta contra o ideal da mulher submissa e frágil (MOURA, 1992).

São poucas as pessoas que realmente conhecem a vida na noite e que já conversaram com uma prostituta ou cliente. Há várias tentativas de explicar tal fenômeno, mas nem sempre baseados em saberes de experiência, mas com base em preconceitos e julgamentos morais, ao invés de reconhecer essa prática, acabam por ocultá-la (SOUSA, 2007).

As profissionais do sexo trabalham, na maioria das vezes em locais que não lhes oferecem condições de trabalho adequadas ao exercício de sua atividade, enfrentam situações muito precárias de higiene e segurança. O preço do programa, que varia de acordo com a qualidade do serviço inclui também o valor do aluguel do quarto, com higiene precária e limpeza quase inexistente do ambiente, onde lençóis e toalha não são substituídos com frequência, forma de transmissão de diversas doenças (SILVA; COSTA; NASCIMENTO, 2010).

A violência praticada pelos clientes também é outra situação bastante 
citada, destacando-se: o xeixo (quando o cliente não quer pagar o combinado); exigência de modalidade de sexo recusada pela profissional (oral e/ou anal); ou a violência moral, quando a mulher sente-se humilhada (SILVA; COSTA; NASCIMENTO, 2010).

Na prostituição, o não pagamento pelo programa significa um desprezo total da mulher, pois as atividades realizadas não são sequer respeitadas como profissionais (RUSSO, 2007).

A previdência social estuda pontos na perspectiva de legalizar a ocupação, mas levanta alguns problemas, como por exemplo, o reconhecimento dos profissionais do sexo vivendo com HIV. O uso de preservativo não elimina o risco de contágio por completo. Dessa forma, o profissional do sexo vivendo com HIV coloca em risco a comunidade e explicaria, por exemplo, o direcionamento para reabilitação profissional do segurado. Mas esta solicita que o beneficiário apresente escolaridade apropriada e competências que, dependendo do estado de vulnerabilidade social a que está sujeita grande parte dos profissionais, impossibilitaria a reabilitação e resultaria em aposentadoria por invalidez (WESTPHAL; BARBOSA, 2012).

Os autores citam outra questão, a do trabalho de gestantes, caso em função da gravidez a profissional estivesse impedida de exercer seu ofício, estaria, em tese, caracterizada a incapacidade para o trabalho. Assim, o simples reconhecimento da profissão repercute na instituição previdenciária, que não dispõe de dados epidemiológicos e estudos para prever a repercussão da legalização dessa profissão para o Instituto Nacional do Seguro Social.

\section{Referências}

ALVES, F. L. Etnografia dos usos sociais do corpo da garota de programa. In: Revista Latinoamericana de Estudos sobre Cuerpos, Emociones y Sociedad - RELACES, Córdoba, n. 7. ano 3. p. 07-16, Dezembro-2011/março2012.

AQUINO, P. S. et al. Perfil sociodemográfico e comportamento sexual de prostitutas de Fortaleza - CE. Texto contexto - enferm., Florianópolis , v. 17, n. 3, p. 427-434, set. 2008. Disponível em: 
07072008000300003\&lng=en\&nrm=iso>. Acesso em: 06 ago. 2014.

AQUINO, P. S.; NICOLAU, A. I. O.; PINHEIRO, A. K. B. Desempenho das atividades de vida de prostitutas segundo o Modelo de Enfermagem de Roper, Logan e Tierney. Rev. bras. enferm., Brasília, v. 64, n. 1, fev. 2011. Disponível em:

$<$ http://www.scielo.br/scielo.php?script=sci_arttext\&pid=S0034$71672011000100020 \& \operatorname{lng}=\mathrm{en} \& \mathrm{nrm}=\mathrm{iso}>$. Acesso em: 06 ago. 2014.

BARRETO, L. C. Prostituição, gênero e sexualidade: hierarquias sociais e enfrentamentos no contexto de Belo Horizonte. 2008. 154 f. Dissertação (Mestrado em Psicologia), Faculdade de Filosofia e Ciências Humanas, Universidade Federal de Minas Gerais, Belo Horizonte, 2008.

BARRETO, L. C. Somos sujeitas políticas de nossa própria história: Prostituição e feminismos em Belo Horizonte. 2015. 287 f. Dissertação (Doutorado Interdisciplinar em Ciências Humanas), Centro de Filosofia e Ciências Humanas, Universidade Federal de Santa Catarina, Florianópolis, 2015.

BARRETO, L. C.; GROSSI, M. P.; MAYORGA, C. Pensando a Prostituição, a Pesquisa e a Militância. Anais do III Seminário Internacional Enlaçando Sexualidades, Salvador, Bahia, UNEB, junho 2013. Disponível em: $<$ http://www.uneb.br/enlacandosexualidades/files/2013/06/Pensando-aprostitui\%C3\%A7\%C3\%A3o-a-pesquisa-e-a-milit\%C3\%A2ncia.pdf>. Acesso: em: 31 jul. 2017.

BRASIL. IBGE. Censo Demográfico, 2010. Disponível em: $<$ https://cidades.ibge.gov.br/brasil/mg/uberlandia/panorama>. Acesso em: 01 dez. 2017.

Ministério da Saúde. Secretaria de Políticas de Saúde. Coordenação Nacional de DST e Aids. Profissionais do sexo: documento referencial para ações de prevenção das DST e da Aids / Secretaria de Políticas de Saúde, Coordenação Nacional de DST e Aids. Brasília: [s.n.], 2002.

Ministério da Saúde. Portaria n. 1823, de 23 de agosto de 2012. Aprova a Política Nacional de Saúde do Trabalhador. Diário Oficial [da República Federativa do Brasil]. Brasília, 24 ago. 2012; Seção 1, p.46-51.

- Ministério do Trabalho e Emprego. 2017. CBO (Classificação Brasileira de Ocupações) Profissionais do sexo. Disponível em: < http://www.mtecbo.gov.br/cbosite/pages/pesquisas/ResultadoFamiliaDescrica o.jsf>. Acesso em: 27 jul. 2017.

BRITO, J. Resumo sobre "Exclusão Social e a nova desigualdade". 2008. Disponível em: <http://ppgpsi-ufes.blogspot.com.br/2008/09/resumo-sobreexcluso-social-e-nova.html>. Acesso em: 30 jul. 2017. 
Dourados-MS: UFGD, 2015.

COSTA, A. B. et al. Situação de saúde de profissionais do sexo em um município do norte do Paraná. Rev. Odontologia (ATO), Bauru, v. 14, n. 4, p. 257-276, abr. 2014. Disponível em:

$<$ http://www.actiradentes.com.br/revista/2014/textos/15RevistaATO-

Saude_e_Sexo-2014.pdf>. Acesso em: 06 ago. 2014.

CUNHA, L. A. Mulheres em situação de prostituição: um desafio à inclusão. Disponível em:

$<$ http://proex.pucminas.br/sociedadeinclusiva/VIseminario/trabalhos.php $>$. Acesso em: 31 ago. 2014.

DAMACENA, G. N.; SZWARCWALD, C. L.; BARBOSA JUNIOR, A.

Implementation of respondent-driven sampling among female sex workers in Brazil, 2009. Cad. Saúde Pública, Rio de Janeiro, v. 27, supl. 1, 2011. Disponível em:

$<\mathrm{http}: / / \mathrm{www}$.scielo.br/scielo.php?script=sci_arttext\&pid=S0102-

311X2011001300006\&lng=en\&nrm=iso>. Acesso em: 06 ago. 2014.

DeCS. Descritores em Ciências da Saúde. Disponível em:

$<$ http://decs.bvs.br/cgi-bin/wxis1660.exe/decsserver/>. Acesso em: 12 nov. 2014.

DUARTE, R. O.; VANZ, D. Qualidade de vida das profissionais do sexo de Criciúma, Santa Catarina, Brasil. Congresso Fazendo Gênero 8 - Corpo, Violência e Poder, v. 22, n. 8, p. 1-7, 2008. Disponível em: $<$ http://www.fazendogenero.ufsc.br/8/sts/ST26/Duarte-Vanz_26.pdf $>$. Acesso em: 06 ago. 2014.

ENGEL, M. Meretrizes e doutores. São Paulo: Brasiliense, 2004.

FRANÇA, G. V. Prostituição: um enfoque político-social. [2012]. Disponível em:

$<$ http: $</ /$ www.derechoycambiosocial.com/revista029/Prostitui\%C3\%A7\%C3\% A3o.pdf $>$. Acesso em: 24 ago. 2014.

FONSECA, G. História da Prostituição em São Paulo. São Paulo: Resenha Universitária, 1982, p. 160.

FOUCAULT, M. História da Sexualidade 1: a vontade de saber. Rio de Janeiro: Graal, 1988.

1984. História da Sexualidade 2: o uso dos prazeres. Rio de Janeiro: Graal, História da Sexualidade 3: o cuidado de si. São Paulo: Paz e terra, 2014. 
GARCIA, T. O. Pagando bem, que mal tem? Ponderações sobre a regulamentação da atividade do sexo, marginalização e criminalização. Congresso latino-americano de gênero e religião, 4., 2016, São Leopoldo. Anais do Congresso Latino-Americano de Gênero e Religião. São Leopoldo: EST, v. 4, 2016.

GOUVEIA, R. S. V. et al. Se são prostitutas, por que são felizes? Correlatos materiais da satisfação com a vida. Revista Bioética, Brasília, v. 18, n. 3, p. 603-21, 2010. Disponível em:

$<$ http://www.revistabioetica.cfm.org.br/index.php/revista_bioetica/article/vie w/588/594>. Acesso em: 06 ago. 2014.

GUIMARAES, K.; MERCHAN-HAMANN, E. Comercializando fantasias: a representação social da prostituição, dilemas da profissão e a construção da cidadania. Rev. Estud. Fem., Florianópolis, v. 13, n. 3, p. 525-544, dez. 2005. Disponível em:

$<\mathrm{http}: / / \mathrm{www}$. scielo.br/scielo.php?script=sci_arttext\&pid=S0104026X2005000300004\&lng=en\&nrm=iso>. Acesso em: 06 ago. 2014.

JULIANO, D. El peso de la discriminación debates teóricos y fundamentaciones. In: OSBORNE, R (Ed.). Trabajadoras Del sexo: derechos, migraciones y tráfico en el siglo XXI. Barcelona: Edicions Bellaterra, Cap. 1, p. $43-55,2004$.

MARINS NUNES, P. C. Prostituição, políticas públicas e relações de poder: prostitutas no exercício da sua profissão. IX Seminário Internacional de Direitos Humanos da UFPB, Brasil, out. 2016. Disponível em: $<$ http://www.ufpb.br/evento/lti/ocs/index.php/ixsidh/ixsidh/paper/view/4452/1 784>. Acesso em: 31 jul. 2017.

MOURA, E. B. B. Meretrizes e Doutores: saber médico e prostituição no Rio de Janeiro (1840-1890). Revista de História, São Paulo, n. 125-126, p. 163169, jul. 1992. Disponível em: $<$ http://www.revistas.usp.br/revhistoria/article/view/64347/67018>. Acesso em: 27 jul. 2017.

NICOLAU, A. I. O.; AQUINO, P.S; PINHEIRO, A. K. B. Caracterização social de prostitutas diante da visão integral da saúde. REME Rev Mineira Enferm., Belo Horizonte, v. 12, n. 1, p. 11-16, 2008. Disponível em: $<$ http://reme.org.br/artigo/detalhes/232>. Acesso em: 06 ago. 2014.

NEUHOLD , R. R. O conceito exclusão e seus dilemas. Revista Urutágua (Online), Maringá, PR, Brasil, v. n. 5, p. 19, 2004. Disponível em:< http://www.urutagua.uem.br/005/19soc_neuhold.pdf $>$. Acesso em 27 jul. 2017.

OLIVEIRA, L. Os excluídos existem? Notas sobre a elaboração de um novo conceito. Revista Brasileira de Ciências Sociais, v. 12, n. 33, p. 49-61, 1997. Disponível em:< 
http://www.anpocs.org.br/portal/publicacoes/rbcs_00_33/rbcs33_04>.Acesso em: 31 jul. 2017.

OLTRAMARI, L. C.; CAMARGO, B. V. Representações sociais de mulheres profissionais do sexo sobre a AIDS. Estud. psicol. (Natal), Natal, v. 9, n. 2, ago. 2004. Disponível em:

$<$ http://www.scielo.br/scielo.php?script=sci_arttext\&pid=S1413-

294X2004000200013\&lng=pt\&nrm=iso>. Acesso em: 24 ago. 2014.

PASINI, E. Limites simbólicos corporais na prostituição feminina. Cadernos Pagu, Campinas, SP, n. 14, p. 181-200, 2000. Disponível em:

$<$ https://periodicos.sbu.unicamp.br/ojs/index.php/cadpagu/article/view/86353 51/3145>. Acesso em: 28 jul. 2017.

PERES, W. S. Biossociabilidade contemporânea e a expressão travesti. Revista de Psicologia da UNESP, São Paulo, v. 1, n. 1, p. 8-17, 2002.

PINSKY, C. B.; PEDRO, J. M. (Org.). Nova história das mulheres no Brasil. São Paulo: Contexto, 2012.

PISCITELLI, A. On "gringos" and "natives": gender and sexuality in the context of international sex tourism in Fortaleza, Brazil. Vibrant, v. 1, n. 1/2, p. 87-114, 2004.

PISCITELLI, A. Exploração sexual, trabalho sexual: noções e limites. Seminário: Corpos, sexualidades e feminilidades, UERJ, Rio de Janeiro, setembro de 2012. Disponível em:

<https://www.academia.edu/2390837/EXPLORA\%C3\%87\%C3\%830_SEXUA L_TRABALHO_SEXUAL_NO\%C3\%87\%C3\%95ES_E_LIMITES_paper_apre sentado_no_semin $\%$ C3\%A1rio_Corpos_sexualidades_e_feminilidades_UERJ _setembro_de_2012>. Acesso em: 28 jul. 2017.

PONTIFÍCIA UNIVERSIDADE CATÓLICA DO RIO DE JANEIRO (PUCRio). Breve histórico da Prostituição no Brasil. In: <http://www2.dbd.pucrio.br/pergamum/tesesabertas/0912457_2011_cap_2.pdf>. Acesso em: 27 jul. 2017.

PRIORE, M. L. M. (Org.). História do amor no Brasil. 10. ed. São Paulo: Contexto, 2017.

RAGO, M. Os prazeres da noite. São Paulo: Paz e Terra, 2008.

Do cabaré ao lar: a utopia da cidade disciplinar-Brasil 1890-1930. 4.ed. São Paulo: Paz e Terra, 2014.

RODRIGUES, M. T. A prostituição no Brasil contemporâneo: um trabalho como outro qualquer? Rev. katálysis, Florianópolis, v. 12, n. 1, p. 68-76, jun. 2009. Disponível em:

$<$ http://www.scielo.br/scielo.php?script=sci_arttext\&pid=S1414-

$49802009000100009 \& \operatorname{lng}=\mathrm{en} \& \mathrm{nrm}=\mathrm{iso}>$. Acesso em: 06 ago. 2014. 
RUSSO, G. No labirinto da prostituição: o dinheiro e seus aspectos simbólicos. Cad. CRH, Salvador, v. 20, n. 51, p. 497-514, dez. 2007. Disponível em:

$<$ http://www.scielo.br/scielo.php?script=sci_arttext\&pid=S010349792007000300009\&lng=en\&nrm=iso>. Acesso em: 28 jul. 2017.

SALMERON, N. A.; PESSOA, T. A. M. Profissionais do sexo: perfil socioepidemiológico e medidas de redução de danos. Acta paul. enferm., São Paulo, v. 25, n. 4, p. 549-554, 2012. Disponível em: $<$ http://www.scielo.br/scielo.php?script=sci_arttext\&pid=S010321002012000400011\&lng=en\&nrm=iso>. Acesso emः 06 ago. 2014.

SALES, A. P. L. OLIVAR, José Miguel Nieto. Devir puta: políticas da prostituição nas experiências de quatro mulheres militantes. Cadernos de Campo (São Paulo, 1991), São Paulo, v. 23, n. 23, p. 343-347, dez. 2014. Disponível em:< http://www.revistas.usp.br/cadernosdecampo/article/view/84364>. Acesso em: 26 ago. 2017.

SILVA, E. S. As entrelinhas da inclusão/exclusão social na atualidade: uma discussão conceitual. In: V Jornada Internacional de Políticas Públicas (JOINPP), 2011, São Luís-MA. Anais [da] V Jornada Internacional de Políticas Públicas (JOINPP): Estado, Desenvolvimento e Crise do Capital, São Luís, 22 a 26 de Agosto de 2011. São Luís: UFMA, 2011. P. 1-9.

SILVA, E. F.; COSTA, D. B.; NASCIMENTO, J. U. O trabalho das profissionais do sexo em diferentes lócus de prostituição da cidade. Psicol. teor. prat., São Paulo, v. 12, n. 1, p. 109-122, 2010. Disponível em $<$ http://pepsic.bvsalud.org/scielo.php?script=sci_arttext\&pid=S151636872010000100010\&lng=pt\&nrm=iso >. Acesso em: 31 jul. 2017.

SCHREINER, L. et al. Prevalência de sintomas depressivos em uma amostra de prostitutas de Porto Alegre. Rev. psiquiatr. Rio Gd. Sul, Porto Alegre, v. 26, n. 1, abr. 2004. Disponível em:

$<\mathrm{http}: / / \mathrm{www}$. scielo.br/scielo.php?script=sci_arttext\&pid=S010181082004000100003\&lng=en\&nrm=iso>. Acesso em: 06 ago. 2014.

SOUSA, F. R. Saberes da vida na noite: percepções de mulheres que prestam serviços sexuais sobre o educar-se nas relações com seus clientes. 2007. 166f. Dissertação (Mestrado em Ciências Humanas) - Universidade Federal de São Carlos, São Carlos, São Paulo, 2007. Disponível em: $<\mathrm{http}: / /$ www.processoseducativos.ufscar.br/dissertacao2.pdf $>$. Acesso em: 24 ago. 2014.

TORRES, G. V.; DAVIM, R. M. B.; COSTA, T. N. A. Prostituição: causas e perspectivas de futuro em um grupo de jovens. Rev. Latino-Am. 
Enfermagem, Ribeirão Preto, v. 7, n. 3, jul. 1999. Disponível em: $<\mathrm{http}: / / \mathrm{www}$. scielo.br/scielo.php?script=sci_arttext\&pid=S010411691999000300003\&lng=en\&nrm=iso>. Acesso em: 06 ago. 2014.

TOMURA, M. A prostitute's lived experiences of stigma. J Phenomenol Psychol., Netherlands, v. 40, n. 1, p. 51-84, 2009. Disponível em: $<$ http://home.hccnet.nl/r.ermers/MOPerspectief/doc/Tomura-prostitutestigma.pdf $>$. Acesso em: 23 ago. 2014.

VAINFAS, R. (Org.). História e sexualidade no Brasil. Rio de Janeiro: Graal, 1986.

VILLELA, W. V.; MONTEIRO, S. Gênero, estigma e saúde: reflexões a partir da prostituição, do aborto e do HIV/Aids entre mulheres. Epidemiologia e Serviços de Saúde, Brasília, v. 24, n. 3, p. 531-540, 2015. Disponível em: <http://www.scielo.br/pdf/ress/v24n3/2237-9622-ress-24-0300531.pdf>. Acesso em: 27 jul. 2017.

WESTPHAL, D. L.; BARBOSA, C. M. Trabalhadores Invisíveis: A Situação dos Profissionais do Sexo no Brasil. Revista Jurídica Cesumar-Mestrado, v. 12, n. 2, 2012. Disponível em:

$<$ http://periodicos.unicesumar.edu.br/index.php/revjuridica/article/viewFile/ 2552/175>. Acesso em: 27 jul. 2017.

Recebido em novembro de 2018. Aprovado em novembro de 2018. 